\title{
Training and Development Strategy and Its Role in Organizational Performance
}

\author{
Abdus Sattar Niazi (Corresponding Author) \\ MS Scholar, Iqra University Islamabad Campus, Pakistan \\ Ph: +92 3028500 777, Email: a.niazi55@hotmail.com
}

Received: August 01, 2011 Accepted: August 11, 2011 DOI: 10.5296/jpag.v1i2.862

\begin{abstract}
In the FMCG industry at global level, the business environment has changed with intense pressure on organizations, to become 'Learning Organizations' and stay ahead of their competitions by bringing innovation/reinvention in training and development strategy while emphasizing on planning, designing, implementing and evaluating the training programs.

Carry out an analysis that the objective of training and development is to create learning organizations which ensure that employees through value addition can effectively perform their jobs, gain competitive advantage and seek self growth: this measurable performance resulting from good training and development, shall enhance organizational performance.
\end{abstract}

Keywords: Training and Development, Strategy, FMCG, Organizational Performance 


\section{Introduction}

The objectivity of training and development and its continued learning process has always been leverage with the FMCG industry and now it has become rather an over arching trend of social needs, emphasizing that organizations must inculcate learning culture as a social responsibility. It has been also proved by many studies in the past that there are sound connections between various Training and development practices and different measures of organizational performance (for example, Delery and Doty 1996; Becker and Huselid 1998).

Training and development, has its strategic positioning and it directly contributes towards organizational business goals and objectives. Imparting training through use of new technologies and adapting to innovative training methods, like PI (programmed instructions), computer/simulated games, role playing and audio/visual tools are more effective and therefore same are being extensively used in current training curriculums. These newer techniques combined with conventional methods i.e. lectures, conferences, movie/films and case studies provide effective means used for training and education conducted in particular situations.

\section{Literature Review}

\subsection{Training and Development}

As we know that training and development refers to the process to obtain or transfer KSA (knowledge, skills and abilities) needed to carry out a specific activity or task ; therefore, benefits of training and development both for employer and employees are strategic in nature and hence much broader. In order to meet the current and future challenges of our business, training and development assumes a wide range of learning actions, ranging from training of the employees for their present tasks and more so, knowledge sharing to improve the business horizon and customer's service. It also focuses on their career development, thus expanding individual, group and organizational effectiveness. A comprehensive training and development program helps in deliberating on the knowledge, skills and attitudes necessary to achieve organizational goals and also to create competitive advantage (Peteraf 1993). In fact, in the start of the twenty-first century Human Resource Managers have opined that one of the main challenges they are to confront had involved issues related to training and development (Stavrou, Brewster and Charalambous 2004).

\subsection{Training and Development and its Process}

In order to ensure that our employees are equipped with the right kind of skills, knowledge and abilities to perform their assigned tasks, training and development plays its crucial role towards the growth and success of our business. By choosing the right type of training, we ensure that our employees possess the right skills for our business, and the same need to be continuously updated in the follow up of the best and new HR practices. To meet current and future business demands, training and development process has assumed its strategic role and in this regard few studies by Stavrou et al.'s (2004) and Apospori, Nikandrou, Brewster and Papalexandris's (2008), have attained much importance as these highlight the T\&D practices in cross-national contexts. Apospori et al. (2008) had deduced that there is a considerable 
impact of training on organizational performance. Differently from these studies, Cunha, Morgado and Brewster (2003) were the only ones who could not determine the impact of training on organizational performance, and suggested that another study on analysis of this relationship was needed.

\subsection{Need of Developing the Employees}

Jackson (2002) opined that some cultural assumptions underlie human resource management with regards to developing employees: he deliberated through an example which highlighted the distinction between the hard and soft approaches on developmental aspects, appearing in the strategic HRM literature. The hard approach assumed the employees in the organizations as mere resources to achieve the objectives of the organization, where as the soft approach viewed the employees more as valued assets capable of development (Tyson and Fell 1986; Hendry and Pettigrew 1990). The need for developing our employees is compelling because a sound Training and Development plan has its contributions to increase productivity and quality of work. The development strategy reduces staff turnover and absenteeism and also helps in improving motivation among the employees. In order to stay ahead of our competition, training and development plan must incorporate innovation and reinvention and this is only possible when training encompasses a wide range of learning actions. Therefore, an ideal training shall become part of a company-wide strategy and it must be is linked to business goals and organizational performance.

\subsection{Approaches to $T \& D$}

\subsubsection{Reactive Approach}

The traditional approaches to training can be generally termed as reactionary, driven by tactical delivery of technical skills in bricks and mortar, classrooms trainings and where training is seen as an event oriented activity.

\subsubsection{Proactive Approach}

In the learning organization this approach aligns all learning activities with the corporate business strategy, and its focus is on developing competencies.

\subsubsection{Active Learning Approach}

In this approach, trainees play a leading role in learning by exploring issues and situational problems under the guidance of their facilitator. The trainees learn by asking thought provoking questions, searching for answers, and interpreting various observations made during the process. The active learning approach has its lasting impact on learning since it helps in long-term retention and finding better solutions in the challenging situations.In today's fast paced world, continuous learning is essential to success. Individuals need to learn to succeed in life and at work. Companies need to ensure their employees continue to learn, so they can keep up with increased job demands and so the company can gain or maintain competitive advantage. 


\subsection{Changes in Technology and Line Manager's Involvement}

Frequent changes in technology and job design along with the increasing importance of learning and knowledge-based organizations, transform training and development process into an increasingly important facet of human resource development. In this, both the line mangers and trainees are made to learn and identify the training and development needs through needs assessments and further, jobs/tasks are analyzed to determine and fix the training and development objectives. Thereafter, training and development programs are designed while using innovation in different techniques or methods. Implementation is most important activity followed by evaluation of training and development programs.

\section{Discussion}

\subsection{Learning Organization and its Strategic T\&D Alignment}

Training and development process includes a wide range of learning actions and therefore to develop an organization with a strategic focus, it becomes a model of learning organization. In order to maintain and nurture such organizations, we require strategic focus on the needs of learning, both for the employer and the employee. In order to create a win-win situation both for the organization and the employee, the employer must consider the learner (the employee) as a vital investment for organization's successful performance. In these organizations, a direct linkage between the organization's mission and its learning culture, benefits both the employer and the employee, highlighting the positive associations of learning, motivation and organizational performance. The learning organization therefore requires an environment that supports growth for individual capability and experience and, at the same time, increases business performance. For a learning organization to become effective, it is necessary that leadership support and guidance for continuous learning is vital, specially steered by the CEO. Therefore, it is proposed:

\section{Hypothesis 1: Learning organization and its strategic T\&D alignment will be positively related to organizational performance.}

\subsection{Training Need Analysis (TNA) and Line Manager Active Involvement in TNA}

There is need to have proactive approach to TNA in which involvement of Line Manager is more meaningful since he/she is required to document the training needs and also carry out cost benefit analysis while deliberating the return on investment vis-à-vis training costs. Therefore, analyzing training needs and the tools for measuring the effectiveness are important and hence an alignment of strategic and training objectives of the organization is ensured. TNA provides a benchmark (pre-measure) of the skills trainees have before training and the same can be compared to a measure of the skills acquired in training (post-measure) which highlights the cost savings or value additions achieved as a result of training (Cascio 1991). TNA ensures that training focuses on those skills which are to be acquired by the trainees to perform their assigned jobs. The trainings must be relevant, and organized in a manner that an interest and value is created to ensure active participation by the trainees.

Such trainings must be avoided which are not required by the employees, who if sent forcibly, will not be taking them seriously. Therefore a good TNA achieves its objectivity by ensuring 
that only those who need the training, are included and this training template provides complete details respecting each trainee, as to why the training is needed (Blanchard and Thacker 1999). Therefore, it is proposed:

Hypothesis 2: Training Need Analysis (TNA) and Line Manager's active involvement in TNA will be positively related to organizational performance.

\subsection{Training Formalization Including Implementation and Its Evaluation}

The new trends and current business challenges have created the need for strategic approaches to training and development. HRD Department must have the ability to formalize training and development plan, its alignment with the business strategy, and its implementation and evaluation to enhance organizational performance. Training and development does not take place in a void but within specific contexts as perceived by scholars. Many studies demonstrate the importance of understanding the human behaviors (for example, see Ronen and Shenkar 1985; Whitley 1999; Hofstede 2001; Ignjatovic and Svetlik 2003; House, Hanges, Javidan, Dorfman and Gupta 2004). There are human resource practices which are considered important in one scenario but the same may be considered less important in the other (Youndt, Snell, Dean Jr. and Lepak 1996; Ferris, Hochwarter, Buckley, Harrell-Cook and Fink 1999). We have to understand that at the organizational level, culture, values and work force diversity are major features which affect the relationships between training and development and organizational performance. Similarly, ownership, size, technology and organizational structure are few other features which influence HRD activities and organizational performance (Fombrun, Tichy and Devanna 1984; Delery and Doty 1996). Therefore, it is proposed:

Hypothesis 3: T\&D formalization including its implementation and evaluation will be positively related to organizational performance.

\subsection{Employee Performance and Training and Development Activities}

Today, the relationship between the organization and the employee has changed. A greater importance is attached to the value of individuals and the team contributions, to find effective business solutions which play key role towards successful organizational performance. The employee is viewed as a 'learning customer', bringing personal preferences and motivation to the workplace, and thereby displaying innovation in his managerial skills. There are positive relationships between training and development strategies and organizational performances; and job satisfaction, competitive advantage and measured performances are the important levers to attain employee's good performance. Performance orientation was included as an important association in training, in a number of studies ( Aycan 2003; House et al. 2004; Javidan 2004). In case of learning organizations, training has been linked to both corporate strategy and organizational performance: training must be aligned to organizational strategy in order to result in high performance (Delery and Doty 1996). The strategic formalization of training facilitates organizations to analyze and carry out effective internal and external scanning of their work environments (Lyles, Baird, Orris and Kuratko 1993): clearly defined vision/mission statements and organizational strategies are part of the strategic planning 


\section{I Macrothink}

Journal of Public Administration and Governance

ISSN 2161-7104

2011, Vol. 1, No. 2

process which contributes towards the development of specific functional strategies needed to achieve business objectives. Strategy formulation is important in the development of HR strategies needed to attract and retain the human capital required for gaining competitive advantage (Poole and Jenkins 1996). Therefore, it is proposed:

Hypothesis 4: Employee performance (job satisfaction, competitive advantage and measurable performance being its levers) will mediate the relationships positively between T\&D activities and organizational performance.

\section{Research Design}

The general idea behind this method is that organizational performance (dependent variable) is affected by three Independent Variables and one Mediating Variable (Refer Fig:1)

\subsection{Independent Variables}

These are three variables listed as:

- Learning organization and its strategic T\&D alignment.

- Training Need Analysis and line manager's active involvement in Training Need Analysis.

- Training formalization including implementation and its evaluation. 


\title{
Proposed Research Design
}

\author{
for \\ Training and Development Strategy \\ vis-à-vis \\ Organizational Performance
}

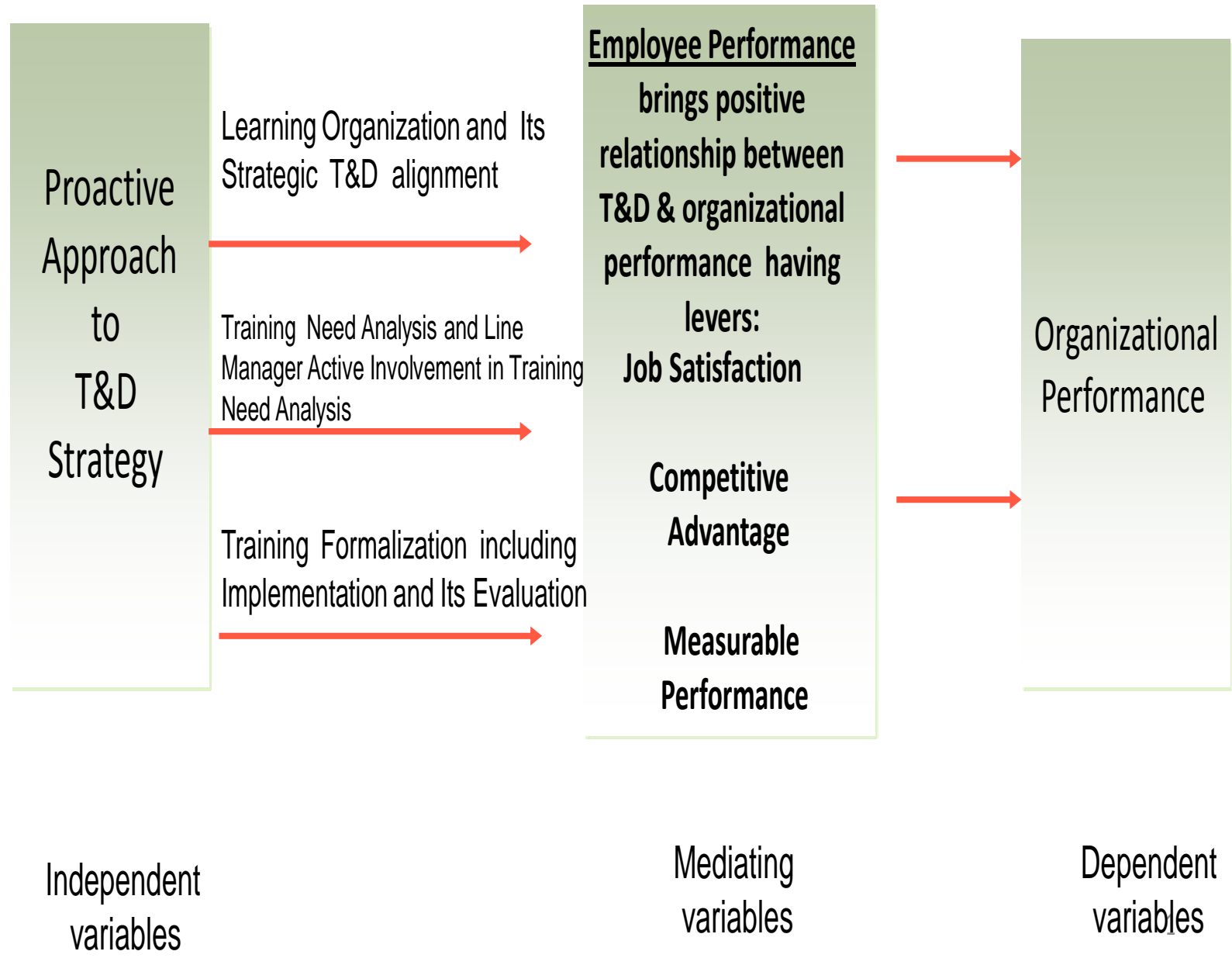




\subsection{Mediating Variable}

Employee Performance has positive relationship between training and development and organizational performance, having job satisfaction, competitive advantage and measurable performance as its three levers.

\subsection{Dependent Variable}

In our research design, we need to focus on organizational performance which is a dependent variable and an outcome of good training and development strategy being implemented.

\subsection{Survey Instrument}

The present study uses hierarchical linear modeling for the analysis of the single-level data which has been collected through Questionnaire (Annex A), used as instrument.

\subsection{Convenience Sampling}

A convenience sample of 100 employees from different departments of an FMCG multinational company was selected who were given a Questionnaire to be completed in own time and same returned after three days. Response rate was $77 \%$. The survey was organized around four sections (for each hypothesis) covering the important aspects of learning organization and its strategic T\&D alignment, training need analysis and line manager's active involvement in TNA, training formalization including its implementation and evaluation, and employee performance having job satisfaction, competitive advantage and measurable performance as it three levers.This study, used data obtained from employees from four different departments i.e, Finance, HR, Supply Chain and Sales \& Marketing of a leading FMCG company, of which 10-15 employees each department participated in the survey. The summary of results is given in Table 1(for responses). The reflection of each hypothesis (all proved as true) is also shown in histograms at Figs: 2-5. 


\section{Table-1: Summary of Survey Results}

\section{Training and Development Strategy and Its Role in Organizational Performance}

77 employees had participated in the survey and their responses showing level of importance against each question (5 degree likert scale ranging from Strongly(S) Agree -- Agree -Neutral - Disagree - Strongly(S) Disagree) were recorded and there after a summary was prepared for each hypothesis to draw histograms and conclude findings.

\begin{tabular}{|c|c|c|c|c|c|}
\hline Questions & S.Agree & Agree & Neutral & Disagree & S.Disagree \\
\hline \multicolumn{6}{|l|}{ Learning Organization \& Strategy-H1 } \\
\hline $\begin{array}{l}\text { 1. Do you think that your company is learning organization } \\
\text { which provides strategic umbrella for developing its } \\
\text { employees? }\end{array}$ & 5 & 15 & 34 & 18 & 5 \\
\hline $\begin{array}{l}\text { 2. Did your company have a T\&D strategy aligned with } \\
\text { organization's business strategy? }\end{array}$ & 8 & 37 & 19 & 8 & 5 \\
\hline $\begin{array}{l}\text { 3. Is there any competency directory issued in your } \\
\text { department, as aligned with T\&D strategy and PMS? }\end{array}$ & 11 & 37 & 19 & 8 & 2 \\
\hline \multirow{2}{*}{$\begin{array}{l}\text { 4. What is the general feeling in the organization regarding } \\
\text { meeting its strategic goals and objectives successfully? }\end{array}$} & 14 & 36 & 16 & 7 & 4 \\
\hline & 38 & 125 & 88 & 41 & 16 \\
\hline \multicolumn{6}{|l|}{$\underline{\text { TNA and Goal/objectives-H2 }}$} \\
\hline $\begin{array}{l}\text { 5. Were you assigned the yearly goals and objectives in the } \\
\text { beginning of the year? }\end{array}$ & 9 & 19 & 28 & 16 & 5 \\
\hline $\begin{array}{l}\text { 6. Did your LM/supervisor conduct TNA session in the end of } \\
\text { the year indicating gaps in performance? }\end{array}$ & 11 & 33 & 14 & 12 & 7 \\
\hline 7.Were you recommended for training by $L M / H R$ for the year? & 14 & 33 & 18 & 7 & 5 \\
\hline $\begin{array}{l}\text { 8.What is the team pressure in your department for meeting } \\
\text { goals and objectives productivity? }\end{array}$ & 7 & 35 & 18 & 9 & 8 \\
\hline \multirow{2}{*}{$\begin{array}{l}\text { 9. Has adequate money/effort been allocated for new training/ } \\
\text { initiatives in your department? }\end{array}$} & 7 & 31 & 20 & 11 & 8 \\
\hline & 47 & 151 & 98 & 55 & 33 \\
\hline \multicolumn{6}{|l|}{ Training Formalization and its Execution- $\mathrm{H} 3$} \\
\hline $\begin{array}{l}\text { 10.Are you happy the way T\&D Program is } \\
\text { conducted/concluded in your organization? }\end{array}$ & 5 & 15 & 32 & 19 & 6 \\
\hline $\begin{array}{l}\text { 11.Are there any opportunities available for LM help if } \\
\text { required in the field of training/assistance for the present job? }\end{array}$ & 8 & 37 & 19 & 8 & 5 \\
\hline \multirow[t]{2}{*}{$\begin{array}{l}\text { 12.Is there any Counseling/couching program so that } \\
\text { employees have someone to go to for help? }\end{array}$} & 8 & 34 & 20 & 8 & 7 \\
\hline & 21 & 86 & 71 & 35 & 18 \\
\hline
\end{tabular}




\begin{tabular}{|l|l|l|l|l|l|}
\hline Employee Performance-H4 & & & & & \\
\hline $\begin{array}{l}\text { 13.Do you have sufficient feedback from your LM to know that } \\
\text { he/she is satisfied with your job performance? }\end{array}$ & 6 & 15 & 32 & 17 & 7 \\
\hline $\begin{array}{l}\text { 14.Are you satisfied with PMS tool used for measuring your } \\
\text { level of performance? }\end{array}$ & 8 & 37 & 19 & 8 & 5 \\
\hline $\begin{array}{l}\text { 15.Do you get any competitive advantage through T\&D } \\
\text { program when comparing the same in competitive } \\
\text { environment? }\end{array}$ & 7 & 35 & 19 & 8 & 8 \\
\hline
\end{tabular}

NOTE. Averages of responses for each hypothesis have been worked out to draw histogram between axis X(Likert scale from Strongly Agree to Strongly Disagree showing 5 levels) and axis Y(Responses of sampled employees).

FIGs: 2-5

Hypothesis 1: Learning organization and its strategic T\&D alignment will be positively related to organizational performance.



Fig 2:Histogram showing inter relationship between axis X(Likert scale from Strongly Agree to Strongly showing 5 levels) and axis Y(Responses of sampled employees) for H1(Proved True). 
Hypothesis 2: Training Need Analysis (TNA) and Line Manager's active involvement in TNA will be positively related to organizational performance.

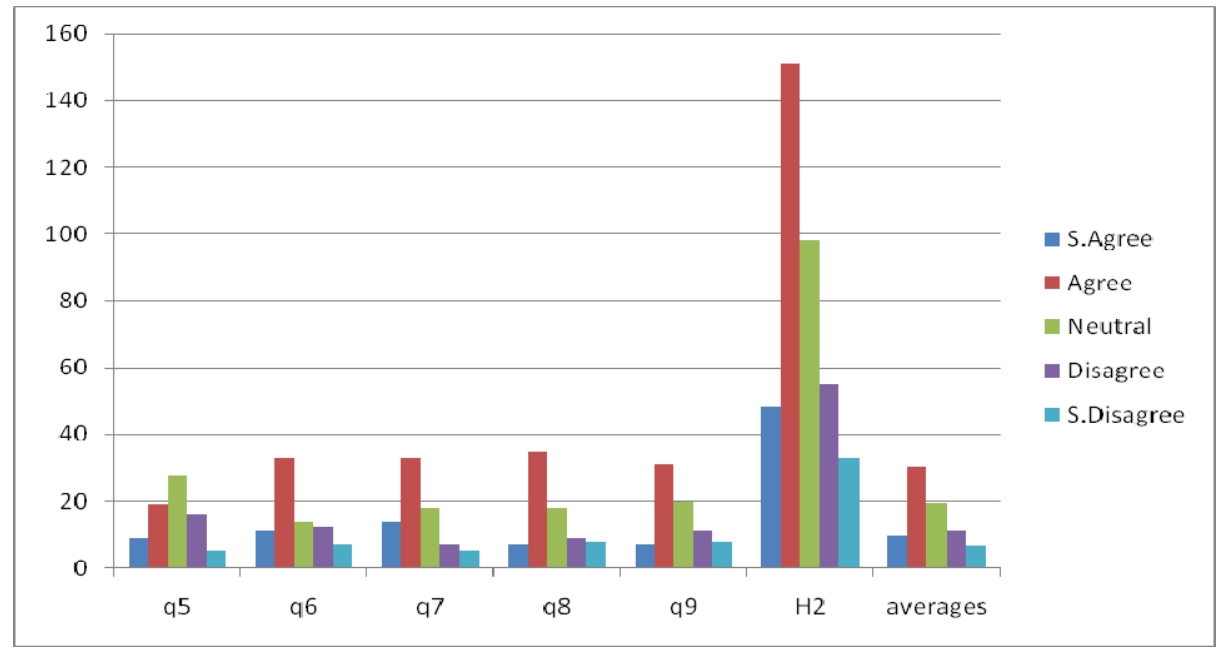

Fig3: Histogram showing inter relationship between axis X(Likert scale from Strongly Agree to Strongly showing 5 levels) and axis Y(Responses of sampled employees) for H2(Proved True).

Hypothesis 3: T\&D formalization including its implementation and evaluation will be positively related to organizational performance.

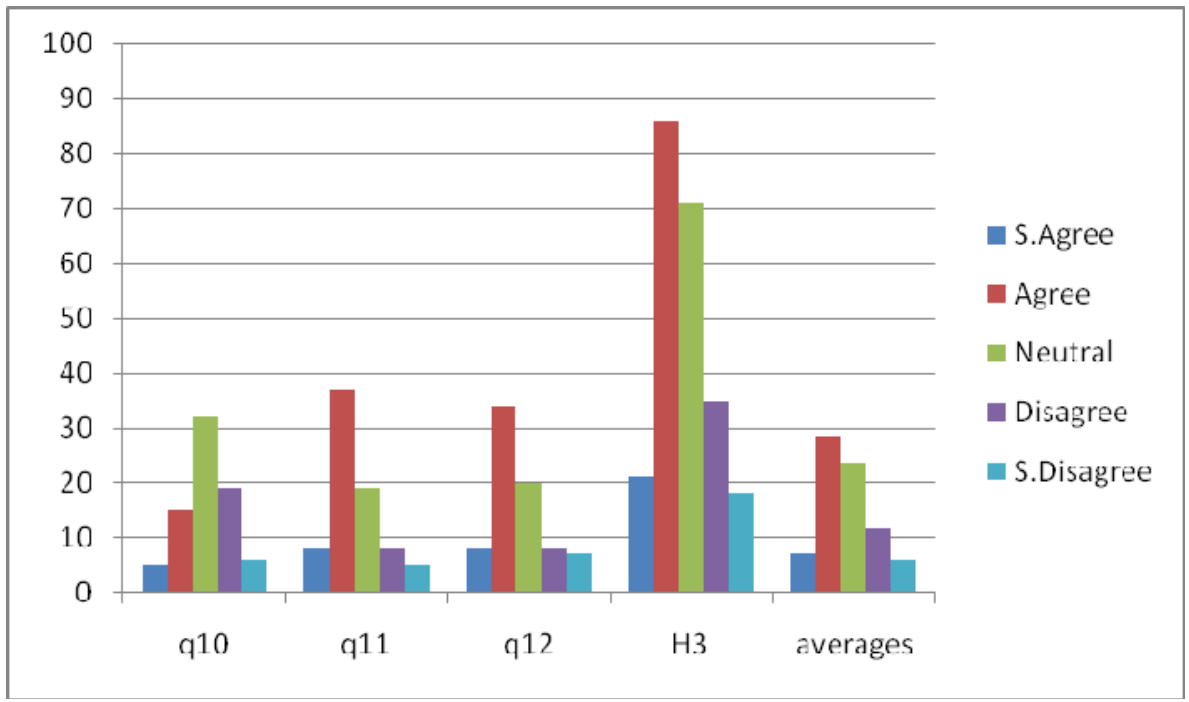

Fig4: Histogram showing inter relationship between axis X(Likert scale from Strongly Agree to Strongly showing 5 levels) and axis Y(Responses of sampled employees) for H3(Proved True). 
Hypothesis 4: Employee performance (job satisfaction, competitive advantage and measurable performance being its levers) will mediate the relationships positively between T\&D activities and organizational performance.

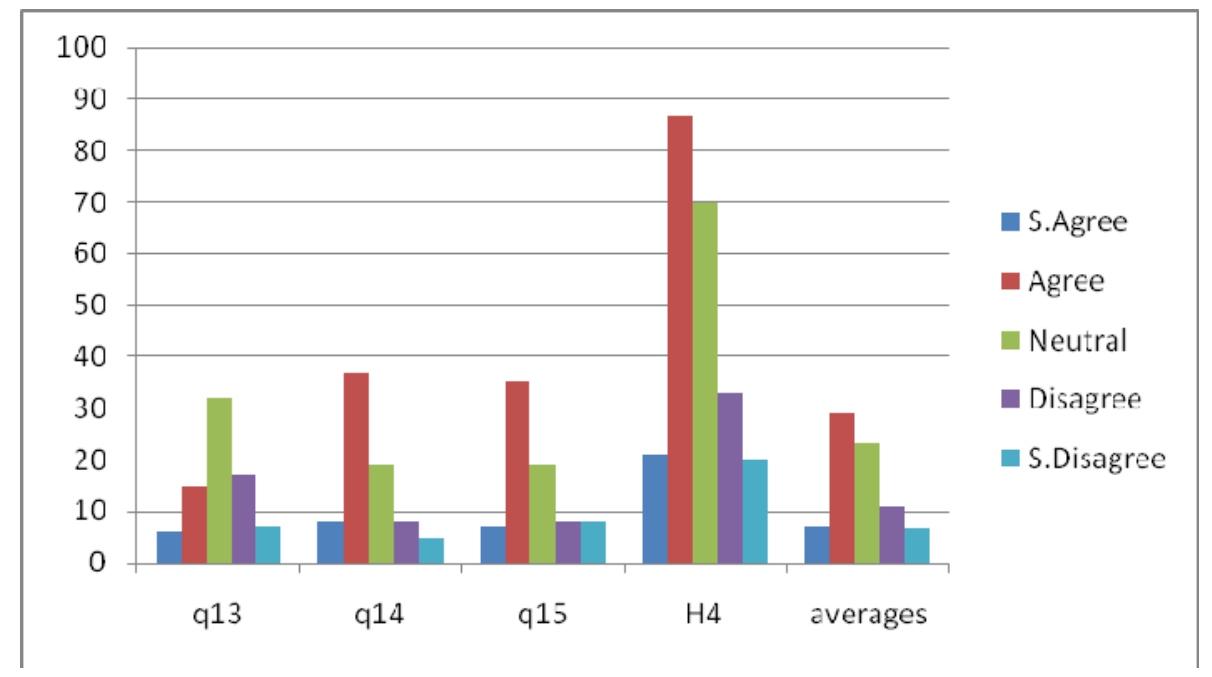

Fig5: Histogram showing inter relationship between axis X(Likert scale from Strongly Agree to Strongly showing 5 levels) and axis Y(Responses of sampled employees) for H4(Proved True).

\section{T\&D Analysis and Findings}

The analysis of the T\&D research revealed that HR's role is to establish and implement a high-level roadmap for strategic training and development. The strategic positioning of training and development directly promotes organizational business goals and objectives, and thereby enhancing organizational performance. The findings emerged as a result of survey are discussed as under:

\subsection{Organizations must focus on continual learning and job trainings}

It is opined that in the developing counties, "learning organization' have their own best learning practice; corporate universities which provide a comprehensive learning infrastructure. Since these are an extension of the organization's learning culture, therefore these corporate universities provide a flexible framework within which training and development strategy is worked out to shape and implement a learning strategy that reflects the heart of the organization's learning culture which positively contributes to organizational performance. 


\subsection{Line managers should be involved in TNA and policy decisions for training}

As training is considered a strategic investment, therefore the line managers should adopt a focused approach towards TNA and remain fully involved in making policy decisions for training, being in line with HR. They must accept their responsibility in this area as front liners when compared with HR managers because they are also accountable to their reports for the training and development, being immediate employee-contacts. It also illustrates that HR department cannot be devolved of the responsibility of training and development, rather it remains committed since deliberated and formal approach to training and development will contribute positively towards organizational performance. Training is necessitated due to rapid advances/changes in technology, developing core competencies, steering downsizing and re-engineering and covering gaps in formal education which all being issues of immediate nature, fall in Line manager's domain.

\subsection{Good training must provides opportunities to learn and grow}

It is not only a social but a moral responsibility of the organization to groom their employees beyond their current roles and offer opportunities to learn and grow, for their career and social mobility. Therefore, HR Managers must align their human capital resources with the business strategies; they should improve workforce skills through strategic training and development process for the organization's successful performance, thereby fueling the need to make trainings more meaningful. The strategic learning imperatives must be developed as aligned with the business objectives which include learning-related important actions, necessary for such organizations which need to attain competitiveness.

\subsection{Employee Performance is augmented through competitive advantage}

The current trends and new business challenges have necessitated the adoption of strategic approaches to training and development which enhance organizational performance. Therefore, HR must develop those areas which contribute positively to employee job satisfaction and give a clear competitive advantage.

\section{Conclusion}

In Pakistan, many companies other than multi-nationals are not meeting the employee demands with reference to training and development and ultimately the gaps found in the required skills vis-a-vis attained skills have become so wide that inter-relationships of training and performance are badly disturbed. There is still a big gap between the knowledge and skills imparted and acquired in the institutions and its applications as seen in the industrial environments. Due to this gap, companies now feel that there should be a close liaison between such institutions and the industry so that employee development programs are made more purpose oriented. There are training institutions which offer customized as well as off-the-shelf programs based on their client's business operations but yet, there is much to be improved. Therefore, training and development cannot be disconnected from the business activities of the organizations; on the contrary, this is the area that clearly illustrates positive relationships between training activities and the organizational performance. 


\section{References}

1. Apospori, E., Nikandrou, I., Brewster, C., and Papalexandris, N. (2008), 'HRM and Organizational Performance in Northern and Southern Europe,' International Journal of Human Resource Management 19, 7, 1187-1207.

2. Aycan, Z. (2003), 'Human Resource Management in Cultural Context', paper presented at the $7^{\text {th }}$ International Human Resource Management Conference, Limerick, Ireland, June.

3. Becker, B.E., and Huselid, M.A. (1998), 'High Performance Work Systems and Firm Performance: A Synthesis of Research and Managerial Implications,' in Research in Personnel and Human Resource Management, ed. G.R. Ferris, Greenwich, CT: JAI Press, pp. 53-101.

4. Blanchard, N.P., and Thacker, J.W. (1999), Effective Training: Systems, Strategies and Practices, Upper Saddle River, NJ: Prentice Hall.

5. Cascio, W. (1991), Applied Psychology in Personnel Management (4th ed.), Upper Saddle River, NJ: Prentice Hall.

6. Cunha, R., Cunha, M., Morgado, A., and Brewster, C. (2003), 'Market Forces, Strategic Management, HRM Practices and Organizational Performance, A Model Based in a European Sample,' Management Research, 1, 1, 79-91.

7. Delery, J.E., and Doty, H.D. (1996), 'Modes of Theorizing in Strategic Human Resource Management: Types of Universalistic, Contingency, and Configurational Performance Predictions,' Academy of Management Journal, 39, 4, 802-835.

8. Ferris, G.R., Hochwarter, W.A., Buckley, M.R., Harrell-Cook, G., and Fink, D.D. (1999), 'Human Resources Management: Some New Directions,' Journal of Management, 25, 3, 385-415.

9. Fombrun, C., Tichy, N.M., and Devanna, M.A. (1984), Strategic Human Resource Management, New York: John Wiley.

10. Hofstede, G. (2001), Culture's Consequences: Comparing Values, Behaviours, Institutions and Organizations across Nations, London: Sage.

11. House, R.J., Hanges, P.J., Javidan, M., Dorfman, P.W., and Gupta, V. (2004), Culture, Leadership and Organizations, The GLOBE Study of 62 Societies, Thousand Oaks, CA: Sage.

12. Ignjatovic, M., and Svetlik, I. (2003), 'European HRM Clusters,' EBS Review, 17, 25-39.

13. Jackson, T. (2002), 'The Management of People Across Cultures: Valuing People Differently,’ Human Resource Management, 41, 455-475.

14. Javidan, M. (2004), 'Performance Orientation,' in Culture, Leadership and 
Organizations, The GLOBE Study of 62 Societies, eds. R.J. House, P.J. Hanges, M. Javidan, P.W. Dorfman and V. Gupta, Thousand Oaks, CA: Sage, pp. 239-281.

15. Lyles, M., Baird, I., Orris, B., and Kuratko, D. (1993), 'Formalized Planning in Small Business: Increasing Strategic Choices,' Journal of Small Business Management, 31, 2, 38-48.

16. Peteraf, M.A. (1993), 'The Cornerstones of Competitive Advantage: A Resource-Based View,' Strategic Management Journal, 14, 3, 179-192.

17. Poole, M., and Jenkins, G. (1996), 'Competitiveness and Human Resource Management Policies,’ Journal of General Management, 22, 2, 1-19.

18. Ronen, S., and Shenkar, O. (1985), 'Clustering Countries on Attitudinal Dimensions: A Review and Synthesis,' Academy of Management Review, 10, 435-455.

19. Stavrou, E., Brewster, C., and Charalambous, C. (2004), 'Human Resource Management as a Competitive Tool in Europe,' working paper, London: Henley College.

20. Tyson, S., and Fell, A. (1986), Evaluating the Personnel Function, London: Hutchinson.

21. Youndt, M.A., Snell, S.A., Dean, J.W. Jr, and Lepak, D.P. (1996), 'Human Resource Management, Manufacturing Strategy, and Firm Performance,' The Academy of Management Journal, 39, 836-841. 
Annex A:

\section{Research Instrument}

\section{TRAINING AND DEVELOPMENT STRATEGY AND ITS ROLE IN OGANIZATIONAL PERFORMANCE}

Name Position Held

Department Company

Please tick below your reaction/your level of importance against each question for 5 degree likert scale ranging as Strongly(S) Agree -- Agree -Neutral - Disagree - Strongly(S) Disagree:

S.Agree Agree Neutral Disagree S.Disagree

\section{Questions}

\section{Learning Organization \& Strategy}

1.Do you think that your company is learning organization which provides strategic umbrella for developing its employees?

2.Did your company have a T\&D strategy aligned with organization's business strategy?

3.Is there any competency directory issued in your department, as aligned with T\&D strategy and PMS?

4.What is the general feeling in the organization regarding meeting its strategic goals and objectives successfully?

\section{TNA and Goal/objectives}

5.Were you assigned the yearly goals and objectives in the beginning of the year?

6. Did your LM/supervisor conduct TNA session in the end of the year indicating gaps in performance?

7.Were you recommended for training by LM/HR for the year?

8.What is the team pressure in your department for meeting goals and objectives productivity?

9. Has adequate money/effort been allocated for new training/ initiatives in your department?

\section{Training Formalization and its Execution}

10.Are you happy the way T\&D Program is conducted/concluded

in your organization?

11.Are there any opportunities available for LM help if required in the field of training/assistance for the present job?

12.Is there any Counseling/couching program so that employees have someone to go to for help?

\section{Employee Performance}

13.Do you have sufficient feedback from your LM to know that he/she is satisfied with your job performance?

14.Are you satisfied with PMS tool used for measuring your level of performance?

15.Do you get any competitive advantage through T\&D program when comparing the same in competitive environment? Remarks (Any T\&D aspect) 